\title{
Prediksi Hasil Tangkapan Ikan Menggunakan Fuzzy Time Series
}

\author{
Ricky Mubarak ${ }^{\text {a1 }}$, Tursina ${ }^{\mathrm{a} 2}$, Enda Esyudha Pratama ${ }^{\mathrm{a} 3}$ \\ ${ }^{a}$ Program Studi Sarjana Informatika Fakultas Teknik Universitas Tanjungpura \\ Jl. Prof. Dr. H. Hadari Nawawi, Pontianak, Kalimantan Barat 78124 \\ ${ }^{1}$ rickymubarak.rmegmail.com \\ ${ }^{2}$ tursina@informatika.untan.ac.id \\ ${ }^{3}$ endadinformatika.untan.ac.id
}

\begin{abstract}
Abstrak
Prediksi hasil tangkapan ikan merupakan suatu cara dalam memperkirakan hasil tangkapan nelayan yang selama ini ditangani oleh Dinas Perikanan Kota Pontianak dengan menggunakan data historis yang tercatat di Dinas tersebut. Data historis tersebut dapat digunakan sebagai faktor memprediksi yang bermanfaat untuk mengambil kebijakan bagi nelayan dan Dinas Perikanan kedepannya, tetapi sebelum sampai ketahap itu dilakukan penelitian untuk menganalisa seberapa baik dan seberapa akurat prediksi yang dihasilkan dari data historis tangkapan ikan yang tercatat selama ini pada Dinas Perikanan Kota Pontianak. Data yang digunakan dalam penelitian ini sebanyak 60 data dari Januari 2014 hingga Desember 2018. Metode yang digunakan dalam prediksi yaitu dengan Fuzzy Time Series dibagi menjadi 5 (lima) tahap, yaitu Fuzzy Set, Fuzzifikasi, FLR (Fuzzy logic Relationship), FLRG (Fuzzy logic Relationship Group), dan Defuzzifikasi. Terdapat 25 interval yang digunakan dalam penelitian ini. Hasil pengujian prediksi menggunakan MAPE (Mean Absolute Percentage Error) yang didapat hasil terbaik dengan melakukan penambahan pada nilai U (Universe of Discourse) sebesar $4 \%$ dengan MAPE 17,1699\% sehingga diperoleh akurasi atau ketepatan sebesar 82,8301\%. Sedangkan hasil pengujian MAPE terendah pada nilai U (Universe of Discourse) sebesar 0\% yaitu 37,6438\%, sehingga nilai akurasi atau ketepatan sebesar $62,3562 \%$.
\end{abstract}

Kata kunci: Prediksi, Fuzzy Time Series, hasil tangkapan ikan, historis, time series

\section{Fish Catch Result Prediction Using Fuzzy Time Series}

\begin{abstract}
Prediction of fish catches is a way of estimating the result of fishermen that have been handled by the Fisheries office of the city of Pontianak using historical data recorded in the service. Such historical Data can be used as a useful predicting factor to take the policy for fishermen and the fisheries department in the future, but before it is discovered it is done research to analyse how well and how Accurate predictions resulting from the historical data of fish catches recorded during this time at the fisheries Department of Pontianak City. The data used in this study was as much as 60 data from January 2014 to December 2018. The methods used in the predictions are the Fuzzy Time Series divided into 5 (five) stages, namely Fuzzy Set, Fuzzifikasi, FLR (Fuzzy logic Relationship), FLRG (Fuzzy logic Relationship Group), and defuzzification. There are 25 intervals used in this study. Prediction test Results using MAPE (Mean Absolute Percentage Error) obtained best results by making additions to the value of U (Universe of Discourse) by $4 \%$ with MAPE $17.1699 \%$ thus obtained accuracy or accuracy of $82.8301 \%$. While the lowest MAPE test results at the U (Universe of Discourse) value of $0 \%$ is $37.6438 \%$, so the value of accuracy or accuracy is at $62.3562 \%$.
\end{abstract}

Keywords: Forecasting, Fuzzy Time Series, fish catches, historical, time series

\section{Pendahuluan}

Nelayan adalah istilah bagi orang-orang yang sehariharinya bekerja menangkap ikan atau biota lainnya yang hidup di dasar, kolom maupun permukaan perairan. Perairan yang menjadi daerah aktivitas nelayan ini dapat merupakan perairan tawar, payau maupun laut. Pada umumnya nelayan di Indonesia sering melakukan aktivitas di wilayah laut. Karena Indonesia memiliki laut yang sangat luas dan banyak sekali sumberdaya berupa ikan yang hidup di laut Indonesia. Hasil tangkapan ikan merupakan objek dari penelitian ini. Lebih Khususnya historis hasil tangkapan ikan.

Pemerintah Indonesia mengatur para nelayan disetiap daerah melalui Kementrian Kelautan dan Perikanan. Kota Pontianak merupakan salah satu kota yang memiliki Dinas Pangan Pertanian Dan Perikanan Kota Pontianak yang mengkoordinir para nelayan di kota tersebut.

Hasil tangkapan ikan berdasarkan data yang dicatat oleh Dinas Perikanan Kota Pontianak berbeda-beda setiap tahunnya. Hal ini disebabkan kondisi ikan yang tidak dapat diprediksi jumlah tangkapannya, kondisi saat melaut, 
dan keberuntungan dalam mendapatkan hasil. Data-data yang dimiliki oleh bidang Dinas Perikanan Kota Pontianak sebenarnya dapat digunakan untuk memprediksi agar dapat mengambil kebijakan untuk kedepannya, tetapi sebelum sampai ketahap itu, diperlukan penelitian dan analisis hasil prediksi agar tercapainya hasil prediksi dengan akurasi yang tinggi. Berdasarkan data historis yang dimiliki oleh Dinas Perikanan Kota Pontianak dapat digunakan metode Fuzzy Time Series untuk memprediksi hasil tangkapan ikan satu periode kedepannya. Penelitian dengan menggunakan metode Fuzzy Time Series hasil tangkapan ikan sudah pernah dilakukan oleh [1], di pelabuhan Perikanan Nusantara Brondong, pada penelitiannya didapat nilai error sebesar $28 \%$ mengguanakn 11 tahun data historis. Oleh karena itu dilakukanlah penelitian untuk menguji seberapa besar tingkat akurasi untuk memprediksi hasil tangkapan ikan dengan menggunakan data historis 5 tahun yang tercatat di Dinas Perikanan.

Prediksi atau forecasting adalah meramalkan, memproyeksikan, atau mengadakan perkiraan/taksiran terhadap berbagai kemungkinan yang akan terjadi pada masa yang akan dating. Peramalan diperlukan dalam proses pengambilan keputusan, sehingga dengan melakukan peramalan akan memberikan dasar dalam perencanaan dan pengambilan keputusan untuk meningkatkan keuntungan serta mencegah terjadinya kerugian [2]. Metode peramalan (forecasting) terdiri dari metode kualitatif dan kuantitatif. Salah satu metode yang termasuk metode kuantitatif adalah metode time series atau runtun waktu. Time series atau runtun waktu adalah himpunan observasi data terurut dalam waktu [3], sedangkan prediksi Data runtun waktu (time series) adalah jenis data yang dikumpulkan menurut urutan waktu dalam suatu rentang waktu tertentu [4]. Oleh sebab itu data yang digunakan dalam penelitian menggunakan Fuzzy Time Series dalam bentuk data historis.

\section{Metode Penelitian}

Penelitian dilakukan dengan beberapa langkahlangkah sistematis, berikut langkah penelitian diperlihatkan pada Gambar 1.

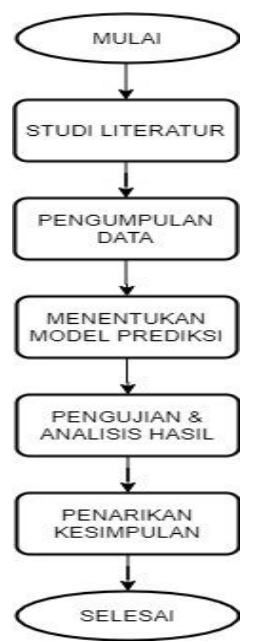

Gambar 1. Metode Penelitian

\section{A. Studi Literatur}

Studi literatur dilakukan dengan mencari referensi ilmu pengetahuan yang berhubungan dengan teknik peramalan (forecasting), Fuzzy Time Series maupun melalui penelitian-penelitian sebelumnya.

\section{B. Pengumpulan Data}

Pengumpulan data dilakukan untuk memperoleh datadata historis hasil tangkapan ikan yang diperoleh dari Dinas Perikanan Kota Pontianak. Data yang digunakan dari Januari 2014 hingga Desember 2018. Data tersebut memiliki catatan hasil tangkapan nelayan harian berdasarkan jumlah hasil tangkapan ikan setiap nelayan.

\section{Menentukan Model Prediksi}

Pada tahapan permodelan prediksi dilakukan beberapa tahapan dalam melakukan perhitungan menggunakan metode Fuzzy Time Series. Langkah-langkah untuk mengimplementasikan metode Fuzzy Time Series dalam memprediksi hasil tangkapan ikan. Memiliki beberapa tahapan dalam memprediksi yang dapat dilihat pada Gambar 2.

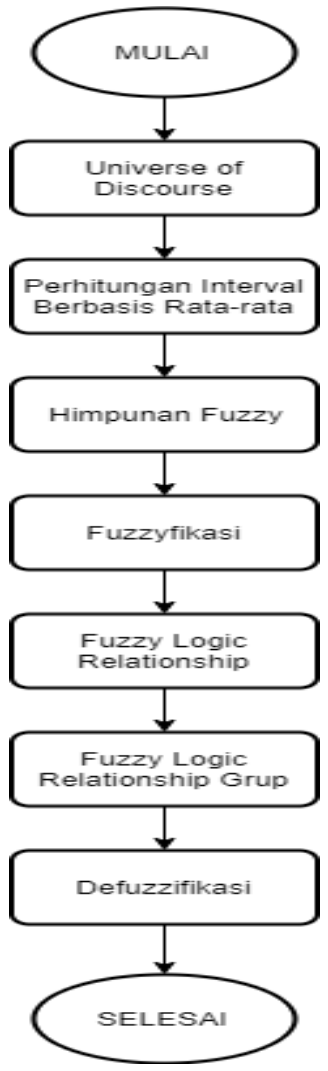

Gambar 2. Diagram Alir Proses Fuzzy Time Series

1) Universe of Discourse: Universe of Discourse (U) sering juga disebut dengan Himpunan Semesta yang berisi seluruh data historis yang akan digunakan dalam melakukan prediksi dari data terkecil hingga data terbesar [5], dalam pengertian lain Universe of Discourse adalah sub proses dari proses yang terjadi pada peramalan dengan menggunakan metode time invariant fuzzy time series [6]. U yang terbentuk pada penelitian ini adalah 
[1053, 9190.23]. Data historis yang digunakan dapat dilihat pada Tabel. I.

TABEL I

DATA HISTORIS

\begin{tabular}{|l|l|l|l|l|l|}
\hline Waktu & \multicolumn{1}{|c|}{ Data } & Waktu & \multicolumn{1}{|c|}{ Data } & \multicolumn{1}{|c|}{ Waktu } & Data \\
\hline Jan-14 & 1172,71 & Jan-15 & 2671,71 & Jan-18 & 6682,5 \\
\hline Feb-14 & 1066,78 & Feb-15 & 3618,8 & Feb-18 & 6816,2 \\
\hline Mar-14 & 1162,53 & Mar-15 & 3930,48 & Mar-18 & 7896,6 \\
\hline Apr-14 & 1276,31 & Apr-15 & 4770,81 & Apr-18 & 6779,8 \\
\hline Mei-14 & 1176,18 & Mei-15 & 4650,8 & Mei-18 & 5649,1 \\
\hline Jun-14 & 1228,98 & Jun-15 & 3950 & Jun-18 & 4856,6 \\
\hline Jul-14 & 1257,54 & Jul-15 & 3385,36 & Jul-18 & 3555 \\
\hline Agu-14 & 1241,54 & $\ldots$ & $\ldots$ & Agu-18 & 3475 \\
\hline Sep-14 & 1053 & Sep-17 & 1269,5 & Sep-18 & 3200 \\
\hline Okt-14 & 1352,29 & Okt-17 & 2030,8 & Okt-18 & 2610 \\
\hline Nov-14 & 1880.97 & Nov-17 & 3901 & Nov-18 & 2960 \\
\hline Des-14 & 1380,29 & Des-17 & 5370,5 & Des-18 & 2530 \\
\hline
\end{tabular}

2) Perhitungan Interval Berbasis Rata-rata: Menentukan interval berbasis rata-rata dengan cara menghitung setengah dari hasil rata-rata nilai selisih antara data historis kemudian dibulatkan [7], cara lain menghitung interval berbasis rata-rata dengan mengurangi nilai terkecil (Xmin) dan menambahkan nilai terbesar (Xmax) [8], berdasarkan Tabel II basis interval. Nilai interval diperoleh dengan membagi nilai jangkauan dengan nilai perhitungan yang tadi telah dibulatkan.

TABEL II

BASIS INTERVAL

\begin{tabular}{|c|c|}
\hline Jangkauan & Basis \\
\hline $0.1-1.0$ & 0.1 \\
\hline $1.1-10$ & 1 \\
\hline $11-100$ & 10 \\
\hline $101-1000$ & 100 \\
\hline
\end{tabular}

Alur dalam menghitung interval dengan berbasis ratarata sebagai berikut :

1. Hitung semua selisih antar data historis dengan persamaan $\mathrm{Ai}+1$ dan $\mathrm{Ai}(\mathrm{i}=1 . ., \mathrm{n}-1)$ kemudian dijumlahkan semua selisih setiap data tersebut.

2. Jumlah selisih kemudian dibagi banyak data selisih, dibagi 2 dan dibulatkan.

Kemudian menentukan jumlah kelas interval yang diperolah dari $D_{\max }-D_{\min }$ dan dibagi dengan nilai panjang interval pada langkah kedua. Kemudian nilai jangkauan dibulatkan sehingga didapat jumlah kelas jangkauan.

$K=\frac{\left(D_{\max }+D_{2}\right)-\left(D_{\min }-D_{1}\right)}{I}$

dengan:

$D_{\max } \quad=$ Nilai terbersar dalam $U$

$D_{\min } \quad=$ Nilai terkecil dalam $U$

$\mathrm{D}_{2} \quad=$ Persentasi dari nilai terbesar

$D_{1} \quad=$ Persentasi dari nilai terkecil

I $\quad=$ Panjang interval

Dari data historis pada Tabel I didapat selisih rata-rata sebesar 686.0337, dari rata-rata tersebut dibagi dua untuk mendapatkan nilai tengah dari rata-rata absolute sehingga didapat hasil menjadi 343.0169 dan dibulatkan berdasarkan basis interval pada Tabel II menjadi 343 sebagai panjang interval efektif. Langkah selanjutnya yaitu mendapatkan jumlah interval pembentukan fuzzy dengan mengurangi nilai batas atas (Dmax) yaitu 9190,23 dan batas bawah (Dmin) yaitu 1053. (Dmax - Dmin $)=$ $(9190,23-1053)=8137,23$ kemudian dibagi panjang interval dan didapatlah $(8137,23 / 343)=23,7237$ dibulatkan menjadi 24 interval.

3) Himpunan Fuzzy: Data historis kemudian akan dikelompokan kedalam keanggotaan fuzzy set yang terbentuk dari proses pembentukan interval [9], grafik fuzzy set yang terbentuk dapat dilihat pada Gambar 3 .

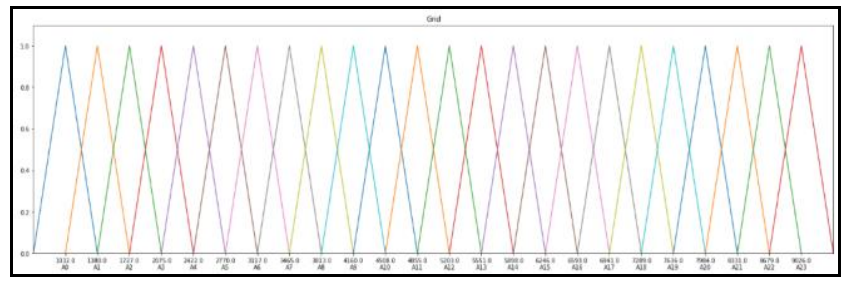

Gambar 3. Fuzzy Set

4) Fuzzifikasi: Nilai fuzzifikasi merupakan nilai tengah dari setiap interval yang terbantuk dari himpunan semesta (U) [10]. Nilai dari setiap fuzzifikasi dapat dilihat pada Tabel III.

TABEL III

NILAI FUZZIFIKASI

\begin{tabular}{|c|c|}
\hline Fuzzy Set ke- & Nilai Fuzzy Set \\
\hline A1 & 1224,01 \\
\hline A2 & 1567,03 \\
\hline A3 & 1910,04 \\
\hline A4 & 2253,06 \\
\hline$\ldots$ & $\ldots$ \\
\hline A20 & 7741,33 \\
\hline A21 & 8084,35 \\
\hline A22 & 8427,36 \\
\hline A23 & 8770,38 \\
\hline A24 & 9113,40 \\
\hline
\end{tabular}

Kemudian hasil dari fuzzifikasi dari data historis berdasarkan fuzzy set dapat dilihat pada Tabel IV.

TABEL IV

FUZZIFIKASI

\begin{tabular}{|c|c|c|}
\hline Waktu & Data & Fuzzifikasi \\
\hline Jan-14 & 1172,71 & A1 \\
\hline Feb-14 & 1066,78 & A1 \\
\hline Mar-14 & 1162,53 & A1 \\
\hline Apr-14 & 1276,31 & A1 \\
\hline$\ldots$ & $\ldots$ & $\ldots$ \\
\hline Agu-18 & 3475 & A8 \\
\hline Sep-18 & 3200 & A7 \\
\hline Okt-18 & 2610 & A5 \\
\hline Nov-18 & 2960 & A6 \\
\hline Des-18 & 2530 & A5 \\
\hline
\end{tabular}

5) Fuzzy Logic Relationship (FLR): Tahap ini menentukan keterhubungan antar data historis setelah melakukan fuzzyfikasi. Jika variable time series $\mathrm{F}(\mathrm{t}-1)$ difuzzifikasi sebagai $A_{i}$ dan $F(t)$ sebagai $A_{j}$, maka $A_{i}$ dihubungkan atau direlasikan dengan $A_{j}$ yang dapat dinyatakan dengan notasi $A_{i} \rightarrow A_{j}$ [11]. Hal ini bisa 
diartikan $A_{i}$ yang terletak pada sisi sebagai kiri relationship disebut dengan current state dan $\mathrm{A}_{\mathrm{j}}$ yang berada pada sisi kanan relationship disebut dengan next state dan jika terjadi perulangan relationship maka akan dihitung hanya sekali. Adapun keterangan FLR ditampilkan pada Tabel V.

TABEL V

FUZZY LOGIC RELATIONSHIP

\begin{tabular}{|c|c|}
\hline Waktu & FLR \\
\hline Jan-14 $\rightarrow$ Feb-14 & A1 $\rightarrow$ A1 \\
\hline Feb-14 $\rightarrow$ Mar-14 & A1 $\rightarrow$ A1 \\
\hline Mar-14 $\rightarrow$ Apr-14 & A1 $\rightarrow$ A1 \\
\hline Apr-14 $\rightarrow$ Mei-14 & A1 $\rightarrow$ A1 \\
\hline$\ldots$ & $\ldots$ \\
\hline Juli-18 $\rightarrow$ Agu-18 & A8 $\rightarrow$ A8 \\
\hline Agu-18 $\rightarrow$ Sep-18 & A8 $\rightarrow$ A7 \\
\hline Sep-18 $\rightarrow$ Okt-18 & A7 $\rightarrow$ A5 \\
\hline Okt-18 $\rightarrow$ Nov-18 & A5 $\rightarrow$ A6 \\
\hline Nov-18 $\rightarrow$ Des-18 & A6 $\rightarrow$ A5 \\
\hline
\end{tabular}

6) Fuzzy Logic Relationship Group (FLRG): Fuzzy logic relationship group merupakan pengelompokan hasil dari fuzzy logic relationship dengan kedua sisi, sisi kiri Current State dan sisi kanan Next State [12]. Semua interval akan menjadi current state mulai dari A1 hingga A24 dan akan berisikan anggota atau yang disebut next state. Setiap next state yang sama tidak dimasukan berulang kali melainkan dihitung menjadi satu next state. Fuzzy logic relationship group dapat dilihat pada Tabel VI.

TABEL VI

FUZZY LOGIC RELATIONSHIP GROUP

\begin{tabular}{|l|l|}
\hline Current State & Next State \\
\hline $\mathrm{A} 1 \rightarrow$ & $\mathrm{A} 1, \mathrm{~A} 3$ \\
\hline $\mathrm{A} 2 \rightarrow$ & $\mathrm{A} 5$ \\
\hline $\mathrm{A} 3 \rightarrow$ & $\mathrm{A} 2, \mathrm{~A} 5, \mathrm{~A} 9$ \\
\hline $\mathrm{A} 4 \rightarrow$ & $\mathrm{A} 3$ \\
\hline $\mathrm{A} 5 \rightarrow$ & $\mathrm{A} 1, \mathrm{~A} 3, \mathrm{~A} 6, \mathrm{~A} 8$ \\
\hline$\ldots$ & $\ldots$ \\
\hline $\mathrm{A} 21 \rightarrow$ & $\mathrm{A} 17$ \\
\hline $\mathrm{A} 22 \rightarrow$ & $\mathrm{A} 24$ \\
\hline $\mathrm{A} 23 \rightarrow$ & $\mathrm{A} 19$ \\
\hline $\mathrm{A} 24 \rightarrow$ & $\mathrm{A} 23$ \\
\hline
\end{tabular}

7) Defuzzifikasi: Proses deffuzifikasi merupakan proses perhitungan dari hasil output prediksi untuk kemudian dihitung sehingga mendapatkan hasil dengan bilangan crisp [13]. Setelah didapatkan hasil defuzzifikasi yang berupa hasil dari bilangan crisp, kemudian ditambahkan dengan data historis pada satu data sebelumnya sehingga mendapatkan hasil peramlan.

1. Jika semua nilai output nol maka variasi peramalannya adalah 0 .

2. Jika nilai keanggotaan dari ouputnya memiliki satu maksimum, maka pada titik tengah interval dimana nilai ini dicapai adalah variasi peramalan.

3. Jika keanggotaan dari outputnya memiliki dua atau lebih maksimum, maka titik tengah intervalnya digunakan sebagai variasi peramalan.

4. Selain itu dengan menggunakan metode centroid, yaitu : $\mathrm{z}=\left(\Sigma \mathrm{x}^{\wedge} \mathrm{A}\right) / \Sigma \mathrm{A}$ dengan $\mathrm{A}=$ suatu luasan yang memiliki titik berat $\mathrm{x}^{\wedge}$.

Hasil dari defuzzifikasi dapat dilihat pada Tabel VII.
TABEL VII

DEFUZZIFIKASI

\begin{tabular}{|l|l|}
\hline Current State & Forecasted \\
\hline $\mathrm{A} 1 \rightarrow$ & 1546 \\
\hline $\mathrm{A} 2 \rightarrow$ & 2575 \\
\hline $\mathrm{A} 3 \rightarrow$ & 2689 \\
\hline $\mathrm{A} 4 \rightarrow$ & 1889 \\
\hline$\ldots$ & $\ldots$ \\
\hline $\mathrm{A} 20 \rightarrow$ & 6005 \\
\hline $\mathrm{A} 21 \rightarrow$ & 6806 \\
\hline $\mathrm{A} 22 \rightarrow$ & 7034 \\
\hline $\mathrm{A} 23 \rightarrow$ & 7720 \\
\hline $\mathrm{A} 24 \rightarrow$ & 6005 \\
\hline
\end{tabular}

Nilai Prediksi didapat dari rata-rata nilai setiap next state yang diambil berdasarkan pembentukan fuzzy set pada Tabel III.

\section{Pengujian \& Analisis Hasil}

Pengujian yang akan dilakukan dengan menghitung data historis dengan data hasil prediksi menggunakan Mean Absolute Percentage Error (MAPE). Pengertian MAPE adalah ukuran ketepatan relatif yang digunakan untuk mengetahui persentase penyimpangan hasil peramalan [14]. MAPE dihitung dengan menggunakan kesalahan absolut pada tiap periode dibagi dengan nilai observasi yang nyata untuk periode itu dan kemudian nilai tersebut dirata-ratakan [15]. MAPE mengindikasikan seberapa besar kesalahan dalam meramal yang dibandingkan dengan nilai nyata.

$$
M A P E=\frac{100 \%}{n} \sum_{t=1}^{n}\left|\frac{X_{t}-\bar{X}_{t}}{X_{t}}\right|
$$

dengan

$$
\begin{array}{ll}
n & =\text { banyak data } \\
X_{t} & =\text { data observasi nyata pada waktu } \mathrm{t} \\
\widehat{X_{t}} & =\text { data hasil peramalan pada waktu } \mathrm{t}
\end{array}
$$

Analisis hasil dan pengujian dilakukan untuk mengetahui tingkat akurasi dari hasil prediksi dengan menggunakan data historis selama 5 tahun.

Selain itu proses analisis pula melibatkan beberapa penelitian-penelitian sebelumnya sebagai referensi untuk melakukan analisis hasil penelitian.

Perhitungan nilai rata-rata, penggunaan grafik, dan penggunaan persamaan matematis juga digunakan sebagai pendekatan dalam melakukan analisis.

\section{E. Penarikan Kesimpulan}

Penarikan kesimpulan dirumuskan berdasarkan analisis hasil pengujian, penarikan kesimpulan mengacu pada tujuan dari penelitian yang dilakukan. Dari penelitian yang telah dilakukan didapatkan sebuah pengetahuan baru yang dapat dijadikan sebagai bahan penelitian selanjutnya.

\section{HASIL DAN PEMBAHASAN}

\section{A. Hasil Uji Himpunan Semesta}

Pengujian yang dilakukan dalam prediksi hasil tangkapan ikan menggunakan data time series dalam periode 5 tahun pada setiap bulannya, dengan total data yang digunakan sebanyak 60 data historis. Data yang 
digunakan mulai dari Januari 2014 sampai dengan Desember 2018. Dari data prediksi hasil tangkapan ikan dengan menggunakan metode Fuzzy Time Series dengan menggunakan perubahan pada nilai nilai batas atas (Dmax) dan nilai batas bawah (Dmin) mendapati hasil yang berbeda, pembagian panjang interval juga mempengaruhi dalam mendapatkan hasil prediksi yang berbeda-beda. Hasil dari nilai Mean Absolute Percentage Error (MAPE) pada pengujian dari $0 \%$ hingga $10 \%$ dirangkum di dalam Tabel VIII.

TABEL VIII

HASIL PREDIKSI DATA 5 TAHUN

\begin{tabular}{|c|c|c|}
\hline Persentase (\%) & Jumlah Interval & Hasil MAPE (\%) \\
\hline 0 & 24 & 37,6438 \\
\hline 1 & 24 & 17,9942 \\
\hline 2 & 24 & 18,2732 \\
\hline 3 & 25 & 17,6935 \\
\hline 4 & 25 & 17,1699 \\
\hline 5 & 25 & 18,4621 \\
\hline 6 & 26 & 20,7802 \\
\hline 7 & 26 & 19,9033 \\
\hline 8 & 26 & 19,6957 \\
\hline 9 & 26 & 19,8622 \\
\hline 10 & 27 & 20,5656 \\
\hline
\end{tabular}

Berdasarkan Tabel VIII hasil pengujian terbaik berada pada penambahan nilai batas atas dan batas bawah sebesar $4 \%$ dengan nilai MAPE 17,1699. Selain itu juga terdapat grafik perbandingan antara data historis dengan hasil prediksi menggunakan fuzzy time series pada Gambar 4.

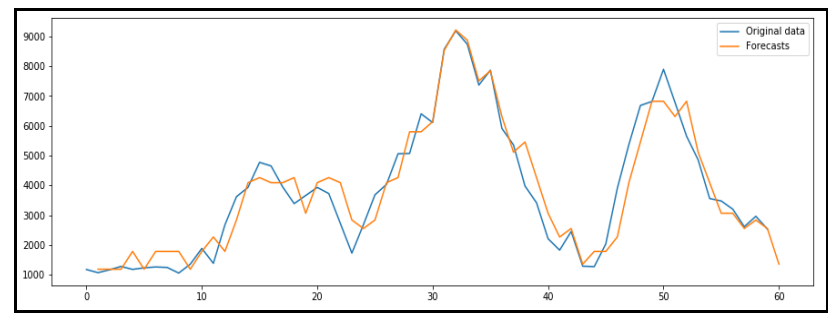

Gambar 4. Grafik Nilai Prediksi dan Data Historis

\section{B. Hasil Uji Data Tahunan}

Selain melakukan pengujian dari data historis 5 tahun, dilakukan pula pengujian prediksi dengan menggunakan data uji 3 tahun dan 4 tahun. Berikut ini tabel hasil pengujian yang telah dilakukan dengan menggunakan data historis 4 tahun. Dari ketiga pengujian dengan jumlah data historis yang berbeda didapat hasil dengan penambahan nilai batas atas dan batas bawah (U) sebesar $4 \%$ memberikan peningkatan pada hasil prediksi, dimana ratarata hasil prediksi sebsar $17 \%$.

\section{Hasil Uji Data Prediksi dan Data Aktual}

Selain menguji dengan metode Mean Absolute Percentage Error (MAPE), ditambahkan pengujian dengan membandingkan data hasil prediksi dengan data historis. Data historis yang digunakan yaitu data Januari 2014 hingga Desember 2017, data prediksi yang diuji dengan data historis atau aktual mulai dari Januari 2018 hingga Desember 2018. Data perbandingan pengujian tersebut disajikan pada Tabel IX.
TABEL IX

Pengujian Data Historis dengan Pembanding Data TAHun Ke-5

\begin{tabular}{|c|c|c|c|c|}
\hline Waktu & Data & Prediksi & Selisih & Persentase \\
\hline Jan-2018 & 6682,5 & 4104,5 & 2578,0 & $39 \%$ \\
\hline Feb-2018 & 6816,2 & 6816,9 & 0,7 & $0 \%$ \\
\hline Mar-2018 & 7896,6 & 6816,9 & 1079,7 & $14 \%$ \\
\hline Apr-2018 & 6779,8 & 5799,7 & 980,1 & $14 \%$ \\
\hline Mei-2018 & 5649,1 & 7244,4 & 1595,3 & $28 \%$ \\
\hline Jun-2018 & 4856,6 & 5652,3 & 795,7 & $16 \%$ \\
\hline Jul-2018 & 3555 & 5298,5 & 1743,5 & $49 \%$ \\
\hline Agu-2018 & 3475 & 3175,8 & 299,2 & $9 \%$ \\
\hline Sep-2018 & 3200 & 3175,8 & 24,2 & $1 \%$ \\
\hline Okt-2018 & 2610 & 3175,8 & 565,8 & $22 \%$ \\
\hline Nov-2018 & 2960 & 1406,8 & 1553,2 & $52 \%$ \\
\hline Des-2018 & 2530 & 2748,3 & 218,3 & $9 \%$ \\
\hline
\end{tabular}

Dilakukan 2 kali pengujian dengan membandingkan hasil prediksi dengan data pada tahun ke-5 atau 2018 mulai Januari hingga Desember dengan menggunakan himpunan semesta (U) $0 \%$ dan (U) $4 \%$.

\section{Analisis Hasil}

Dari pengujian dan Analisis yang telah dilakukan dapat dirangkum keseluruhan beberapa faktor yang mempengaruhi prediksi dengan menggunakan data historis Dinas Perikanan Kota Pontianak sebagai berikut:

1. Setelah melakukan pengujian dari data 3 tahun hingga 5 tahun dengan banyak data 36, 48 data, dan 60 data didapat hasil yang baik pada Universe of Discourse (U) atau himpunan semesta $4 \%$ dengan hasil pengujian terbaik dengan 48 data dan 60 data. Sedangkan pengujian dengan 36 data himpunan semesta $4 \%$ bukan hasil yang terbaik dalam mendapatkan prediksi yang nilai error-nya mendekati nilai pengujian data 4 tahun dan data 5 tahun.

2. Bulan yang sering mendapatkan prediksi yang baik dari pengujian menggunakan 36 data, 48 data, dan 60 data adalah bulan Juli, Agustus, Oktober, Desember 2016.

3. Rata-rata selisih antar data untuk membentuk jumlah interval yang akan digunakan dalam pembentukan fuzzy pada 36 data yaitu 569,4905714, 48 data 678,3678723 , dan 60 data 686,0337288. Jika dirataratakan dari 3 pengujian untuk membentuk jumlah interval tersebut adalah $644,6307242 \approx 645$.

4. Dari pengujian menggunakan data historis hasil tangkapan ikan di Dinas Perikanan Kota Pontianak, jumlah data yang banyak tidak terlalu mempengaruhi hasil prediksi, hal ini dilihat dari pengujian dengan menggunakan data 3 tahun sebanyak 36 data, dengan tingkat error $13,56 \%$ akurasi $86,44 \%$.

5. Hasil pengujian dengan menggunakan data historis selama 4 tahun dan dibandingkan dengan data historis pada tahun 2018 selama 12 bulan menghasilkan akurasi terbaik pada bulan Februari 2018 pada saat nilai batas atas dan batas bawah pada saat $0 \%$ dan $4 \%$. Rata-rata tingkat akurasi prediksi selama 12 bulan pada tahun 2018 saat nilai batas atas dan batas bawah $0 \%$ yaitu $78,96 \%$. Sedangkan rata-rata tingkat akurasi dengan nilai batas atas dan batas bawah $4 \%$ yaitu $82,59 \%$.

\section{KESIMPULAN}


Berdasarkan hasil analisis dan pengujian dalam memprediksi Hasil Tangkapan Ikan Menggunakan Fuzzy Time Series, Rata-rata selisih antar data dalam penelitian ini adalah 645, hal ini yang mempengaruhi dalam pembentukan jumlah interval dan mempengaruhi hasil prediksi. Jika selisih antar data lebih dari rata-rata selisih maka menyebabkan hasil prediksi yang kurang baik.

Hasil prediksi yang baik tidak selalu bergantung pada jumlah data yang banyak seperti referensi rujukan penelitian ini, pada pengujian prediksi penelitian ini dengan menggunakan 36 data atau 3 tahun didapat nilai MAPE sebesar $13,56 \%$ yang mendapatkan akurasi sebesar $86,44 \%$ lebih tinggi dari prediksi menggunakan 60 data historis. Pengujian dengan membandingkan data historis tahun ke-5 dengan prediksi setiap bulannya pada tahun ke5 menghasilkan tingkat akurasi yang lebih baik dengan cara menambahkan nilai batas atas (Dmax) dan batas bawah (Dmin) sebesar 4\%, dengan akurasi rata-rata sebesar $82,59 \%$. Hasil dari penambahan nilai batas atas (Dmax) dan nilai batas bawah (Dmin) dipenelitian ini mempengaruhi dalam prediksi yang lebih akurat.

Berdasarkan analisa pengujian hasil perhitungan prediksi menggunakan metode Fuzzy Time Series pada penelitian menggunakan data historis dari Dinas Perikanan Kota Pontianak sangat dipengaruhi oleh jumlah dan panjang interval serta panjang semesta pembicaraan (batas data dari yang terkecil hingga terbesar) atau Universe of Discourse.

\section{DAFTAR PUSTAKA}

[1] F. Teknik, U. Hasyim, \& T. Jombang, "Prediksi Jumlah Tangkap Ikan Di Pelabuhan Perikanan Nusantara Brondong Menggunakan Fuzzy Time Series Model Chen," 2017.

[2] N. Rukhansah, A. Muslim, R. Arifudin, F. Matematika, D. Ipa \& U. N. Semarang, "Peramalan Harga Emas Menggunakan Fuzzy Time Series Markov Chain Model," 2015.

[3] M. N. Saleh, M. A. Irwansyah, M. Eng, H. H. Anra, \& M. Kom, "Implementasi Peramalan Menggunakan Fuzzy Time Series pada Aplikasi Helpdesk Inventaris Perangkat Teknologi Informasi," J. Sist. dan Teknol. Inf., vol. 1, no. 2, 2017.

[4] M. Y. Fathoni, "Implementasi Metode Fuzzy Time Series Cheng untuk prediksi Kosentrasi Gas NO2 Di Udara," J. Sist. Inf. Bisnis, vol. 7, no. 1, 2017

[5] I. Halimi \& W. A. Kusuma, "Prediksi Indeks Harga Saham Gabungan (IHSG) Menggunakan Algoritma Neural Network,' J. Edukasi dan Penelit. Inform., vol. 4, no. 1, 2018

[6] M. Dwi Rachmawati \& L. Anifah, "Prediksi Curah Hujan Menggunakan Metode Average Based dan High Order Fuzzy Time Series di Bandar Udara Juanda,” JIEET, vol. 03, 2019.

[7] A. B. Elfajar, B. D. Setiawan, \& C. Dewi, "Peramalan Jumlah Kunjungan Wisatawan Kota Batu Menggunakan Metode Time Invariant Fuzzy Time Series," J. Pengemb. Teknol. Inf. dan Ilmu Komput. Univ. Brawijaya, vol. 1, no. 2, 2017.

[8] N. Fauziah, S. Wahyuningsih, Y. N. Nasution, E. Smoothing, \& N. Network, "Peramalan Mengunakan Fuzzy Time Series Chen ( Studi Kasus: Curah Hujan Kota Samarinda ),' Statistika, vol. 4, no. 2, 2016.

[9] D. Desmonda, T. Tursina, \& M. A. Irwansyah, "Prediksi Besaran Curah Hujan Menggunakan Metode Fuzzy Time Series," J. Sist. dan Teknol. Inf., vol. 6, no. 4, 2018.

[10] A. S. Sukamto \& W. Setiawan, "Peramalan Saham Berdasarkan Data Masa Lalu dengan Pendekatan Fuzzy Time Series," J. Edukasi dan Penelit. Inform., vol. 4, no. 2, 2018

[11] M. T. Jatipaningrum, "Peramalan Data Produk Domestik Bruto dengan Fuzzy Time Series Markov Chain," J. Teknol., vol. 9 , no. 1,2016 .

[12] H. Tamrin, N. Junaidi, \& S. Hamzah, "Perbandingan Model Chen dan Model Lee Pada Metode Fuzzy Time Series untuk
Prediksi Jumlah Ikan,” J. Teknol. Inform., vol. 1, 2018.

[13] S. Kusumadewi, Analisis dan Desain Sistem Fuzzy Menggunakan Tool Box Matlab. Yogyakarta: Graha Ilmu, 2002.

[14] I. Sungkawa \& R. T. Megasari, "Penerapan Ukuran Ketepatan Nilai Ramalan Data Deret Waktu dalam Seleksi Mode Peramalan Volume Penjualan PT Satriamandiri Citramulia,' ComTech Comput. Math. Eng. Appl., vol. 2, no. 2, 2011.

[15] U. Yudatama \& U. M. Magelang, "Fuzzy Time Series Dan Algoritme Average-Based Length Untuk Fuzzy Time Series and Average-Based Length Algorithm for," J. Teknol. Inf. dan Ilmu Komput., vol. 6, no. 4, 2019. 